\title{
QUALIDADE DE ALGUNS DOMÍNIOS DA VIDA DE IDOSOS QUE TRABALHAM
}

\section{ARTIGO ORIGINAL}

ROCHA, Felipe Queiroz Dias¹, PICCIONE, Marcelo Arruda²

ROCHA, Felipe Queiroz Dias. PICCIONE, Marcelo Arruda. Qualidade de alguns domínios da vida de idosos que trabalham. Revista Científica Multidisciplinar Núcleo do Conhecimento. Ano. 06, Ed. 11, Vol. 09, pp. 132-151. Novembro 2021. ISSN: 2448-0959, Link de acesso: https://www.nucleodoconhecimento.com.br/psicologia/dominios-da-vida, $\quad$ DOI: 10.32749/nucleodoconhecimento.com.br/psicologia/dominios-da-vida

\section{RESUMO}

O envelhecimento é um fenômeno idiossincrático em cada indivíduo que converge em uma série de modificações físicas e psicológicas. Todavia, é possível que os idosos vivam bem e com qualidade mesmo que seu desempenho orgânico esteja deficitário. Assim sendo, a problemática deste artigo está relacionada ao crescimento da valorização da qualidade de vida na velhice. Sendo assim, objetivouse verificar como é a qualidade de alguns domínios da vida de idosos que trabalham. Participaram da pesquisa 36 idosos da cidade de São Paulo, com idade média 71,5 e $\pm 5,4$. Os dados foram coletados acidentalmente. Para isso, foram utilizados 36 questionários WHOQOL idênticos. Para verificar se existe diferença estatisticamente significante o teste não paramétrico do Qui-quadrado foi aplicado. Resultou-se: $83,33 \%$ dos seniores dizem Discordar Totalmente da premissa de que

\footnotetext{
${ }^{1}$ Mestre em Ciências da Educação pela Faculdade de Psicologia e de Ciências da Educação da Universidade do Porto (FPCEUP); Mestre em Educação e Formação de Adultos pela FPCEUP; Psicólogo e Bacharel em Psicologia pela Universidade São Judas Tadeu (USJT).

${ }^{2}$ Especialista em Psicologia do Esporte e da Atividade Física pelo Instituto Sedes Sapientiae. Psicólogo e Bacharel em Psicologia pela Universidade São Judas Tadeu (USJT).
}

RC: 101621

Link de acesso: https://www.nucleodoconhecimento.com.br/psicologia/dominios-davida 
têm uma relação insatisfatória com Deus e também Concordam Totalmente que a sua relação com Deus elimina o seu sentimento de solidão; $63,33 \%$ Concordam Totalmente com a existência de um verdadeiro propósito para a humanidade e 47,22\% dos idosos aceitam Completamente a sua aparência física. Deste modo, pôde-se observar que os idosos trabalhadores têm satisfação na sua qualidade de vida.

Palavras-chave: envelhecimento, qualidade de vida, velhice, seniores.

\section{INTRODUÇÃO}

Qualidade de vida é a concepção de um indivíduo quanto à sua posição na vida segundo os seus próprios valores e padrões diante dos seus objetivos e preocupações no meio sociocultural em que vive. Este conceito detém três pilares diferentes e concomitantemente essenciais, segundo a Organização Mundial de Saúde (OMS): a pluridimensionalidade, a subjetividade e a consideração de pontos negativos e positivos (TRENTINI; XAVIER e FLECK, 2006).

Trata-se de um tema que possui diversos significados nas mais distintas áreas. $\mathrm{Na}$ Psicologia Social, o conceito mediador da experiência subjetiva, e também a maior referência, é o nível de satisfação. Inclusive, houve um crescimento da valorização da qualidade de vida na velhice nos últimos anos (TRENTINI; XAVIER e FLECK, 2006), que será o escopo do presente trabalho segundo a avaliação de uma amostra de idosos trabalhadores.

Por sua vez, o processo de envelhecimento pode ser classificado de três modos. O primeiro é denominado de velhice com patologia e é caracterizado pela presença de uma síndrome, doença ou deficiência crônica, a qual limita criticamente o desempenho cotidiano do indivíduo idoso e desvanece as capacidades tidas enquanto jovem adulto (TRENTINI; XAVIER e FLECK, 2006).

O segundo é a velhice usual ou normal e trata-se do processo de envelhecimento comum acompanhado de patologias físicas e/ou mentais numa proporção branda

RC: 101621

Link de acesso: https://www.nucleodoconhecimento.com.br/psicologia/dominios-davida 
em sua manifestação, de maneira a provocar apenas alterações parciais no cotidiano dos idosos (TRENTINI; XAVIER e FLECK, 2006).

O terceiro é conhecido como velhice bem-sucedida ou ótima e é compreendido como a chegada a este estágio com a preservação do estado físico de saúde como dos adultos jovens, o qual toma uma condição boa ou ótima com respeito ao bemestar social e pessoal como exemplo (TRENTINI; XAVIER e FLECK, 2006).

À medida que o tempo passa é cada vez maior o número de idosos no mundo. No Brasil a situação não é diferente e pouco a pouco o mito de que somos um país de jovens tem sido desconstruído (NERI, 2001a).

O envelhecimento biológico é um fenômeno idiossincrático em cada indivíduo, e não uma patologia. É possível que os idosos vivam bem e com qualidade mesmo que seu desempenho orgânico esteja fragilizado ou deficitário (MARTINS et al., 2007).

Ademais, envelhecer converge numa série de modificações de ordem psicológica, além das físicas, que podem culminar em: resistência ou não aceitação em ocupar outras funções; desânimo e problemas com o planejamento do futuro; carência de atendimento em virtude das perdas biopsicossociais e diminuição da autoestima e da boa autoimagem (NERI, 2001b).

Porém, diferente da visão estereotípica negativa e homogeneizadora sobre a velhice, há idosos que sofrem o processo de envelhecimento de forma distinta e relatam a terceira idade como uma fase de prazer. Não se percebe frustrações, conflitos ou dramaticidade no modo como vivenciam esse estágio, assim como não foram identificados sentimentos de rejeição e/ou inferioridade face às mudanças e perdas (JARDIM; MEDEIROS e BRITO, 2019).

$\mathrm{Na}$ verdade, existem alguns mitos sobre a terceira idade, como o de que na velhice os filhos se tornam pais dos próprios pais. Isto não é totalmente verdade, o que ocorre é uma inversão de papéis devido à perda da autonomia, do comando, das 
condições de se determinar, escolher suas leis e objetivos, por parte do idoso (ZIMERMAN, 2000).

Por outro lado, os sujeitos jovens consideram possível haver felicidade na terceira idade e têm até boas concepções acerca de algumas características dos seniores, como no que concerne a sua autoimagem. Todavia, concomitantemente também mostram bastante desassossego no que tangencia a ocorrência deste processo em si, de modo a reportarem que é melhor morrer que vivenciar a angústia e a solidão peculiares deste estágio, pois entendem que a senioridade conjectura a chegada destes estados (RABELO et al., 2008).

Assim, muitos questionamentos são feitos acerca de como a velhice será compreendida globalmente (VELOZ; NASCIMENTO-SCHULZE e CAMARGO, 1999).

O envelhecimento social modifica o status do idoso e o relacionamento dele com outras pessoas (ZIMERMAN, 2000).

O cônjuge, depois de décadas, é um fator importante para a construção desse status social e de repente, na perda do consorte, o sênior se sente sozinho, contrito e desconsolado. Deste modo, o sujeito começa a sofrer por ausência de comunicação expressiva e de atenção, perde o seu papel social e fica à mercê de sensações de inutilidade e de falta de expectativa com a vida (SIMKUNAS e ANJOS, 2001).

Aliás, todos os sujeitos que passaram por tal experiência relatam a solidão como um elemento recorrente, mas reportam que encontraram como alternativa o envolvimento em atividades coletivas, como dança e ginástica, para se manterem em ação e afastar, assim, o estado solitário (SIMKUNAS e ANJOS, 2001).

No fim, o amor está à disposição de todos à medida que é manifesto em comportamentos e sentimentos. Os que se retraem ou se mostram incapazes de se transformar ou evoluir ficam à mercê da solidão e do vazio. Mesmo os que nunca se

RC: 101621

Link de acesso: https://www.nucleodoconhecimento.com.br/psicologia/dominios-davida 
casaram podem e devem procurar parceiros para iniciar uma relação (ALMEIDA e LOURENÇO, 2007).

Um dos eixos constituintes do bem-estar psicológico é a satisfação com a vida, pois considera a perspectiva do próprio sujeito acerca de aspectos da sua realidade. Duas características vitais desta satisfatoriedade são a acurácia de adaptação às insuficiências e o poder de absorver e incorporar em si informações positivas através de uma estrutura psíquica responsável pelo conhecimento de si próprio, denominada de self (NERI, 2001a).

Assim, apenas $40 \%$ dos idosos estão satisfeitos com os seus relacionamentos pessoais, a mesma quantidade que se diz completamente satisfeita com a sua aparência física (COLALTO, 2002).

Sobre este segundo domínio, os idosos se encontram insatisfeitos com seus corpos e manifestam desejos de terem uma aparência mais esbelta, pois este fator é importante em sua adaptação biopsicossocial, já que existem inúmeros estereótipos que os estigmatizam devido ao seu porte físico enfezado. Esses estigmas podem fazer com que o idoso veja seu corpo de maneira distorcida e crie representações negativas (COSTA; BASTOS e SALES, 2008).

No período pós-menopausa, as mulheres sofrem modificações na região genital e no porte físico. Podem ocorrer modificações na forma como o indivíduo vê o seu corpo a ponto de considerar-se deplorável e sem condições de agradar seu consorte, o que gera perturbações emocionais (VERAS, 1995).

As percepções das mulheres idosas acerca da beleza corporal na terceira idade se classificam em três categorias: a beleza verbalizada, a experiência estética perante um espelho e a beleza da mulher na velhice (FIN; PORTELLA e SCORTEGAGNA, 2017).

As mulheres idosas, independente das condições socioeconômicas e culturais, reconhecem como beleza a imagem pautada nos estilos contemporâneos com a 
influência dos padrões estéticos atuais, pois estabelecem um juízo de apreciação no que julgam agradável de ver, sentir e observar (FIN; PORTELLA e SCORTEGAGNA, 2017).

No entanto, a experiência estética do olhar sobre si revela uma dualidade entre imagens apreciadas e depreciadas apresentadas pelas diferentes formas de compreender e sentir a velhice. Ao desvendar a aparência do corpo que envelhece, as mulheres confessam seus sentimentos perante os aspectos dos anos vividos num emaranhado de beleza e fealdade (FIN; PORTELLA e SCORTEGAGNA, 2017).

A beleza na velhice é abstraída como um processo que requer o cuidado de si e de suas relações. Constitui-se num olhar atencioso sobre o corpo e a alma que segue regras, condutas e princípios, tais como a prática de exercícios, a manutenção do bom humor, a dança e a procura do médico quando há algum mal-estar e, até mesmo, a ocupação com o voluntariado. No fim, a percepção da beleza é apreendida na unicidade do ser por meio da valorização e pelo amor dedicado a si próprio (FIN; PORTELLA e SCORTEGAGNA, 2017).

No que concerne à visão disseminada à sociedade por artigos de uma revista popular, foi possível observar de forma hegemônica a consolidação de um discurso que compreende a juventude como um valor a ser conquistado e mantido, ao passo que a velhice é entendida como o resultado da inaptidão de cada um. Ou seja, ser jovem trata-se de uma responsabilidade do público-leitor, que, ao seguir suas recomendações periódicas, não envelhecerá (KUSCHICK e MACHADO, 2016).

Mulheres invejam o corpo, a beleza, a juventude, a magreza e a sensualidade umas das outras. O corpo invejado por elas é jovial, esbelto e atraente. No Brasil, este modelo de corpo é precípuo (GOLDENBERG, 2018).

As mulheres brasileiras estão entre as maiores consumidoras de produtos e serviços estéticos de todo o mundo, tais como cirurgia plástica, toxina botulínica, preenchimentos, tintura para cabelo, remédios para emagrecer e moderadores de apetite. São as que estão mais insatisfeitas com o próprio corpo, e as que mais RC: 101621

Link de acesso: https://www.nucleodoconhecimento.com.br/psicologia/dominios-davida 
deixam de sair de casa, ir a festas e até mesmo de trabalhar quando se sentem velhas, gordas e feias (GOLDENBERG, 2018).

As jovens dizem que cuidarão de si quando chegarem à velhice e que as amigas as ajudarão. Os homens, por suas vezes, dizem que as mulheres de suas famílias farão isso por eles: esposa, filhas e netas (GOLDENBERG, 2018).

Existe também uma ideia de que o envelhecimento é sempre entendido como um advento extrínseco. Ao discorrer sobre a sua própria velhice, a maioria dos seniores reporta-se ao caso como se fosse apenas um fenômeno exógeno. Na verdade, acontece que a compreensão deste estágio somente através da via das restrições físicas provoca sofrimento, angústia e rejeição deste contexto (LIMA, 2007).

Por outro lado, a espiritualidade pode ser considerada um recurso favorável ao bemestar na terceira idade, pelo que a participação em ambientes motivadores e a presença de oportunidades de progresso, aliadas com os fatores espirituais, têm se mostrado fulcrais neste estágio. A religiosidade pode estar associada a uma maior resiliência na velhice (MARGACA e RODRIGUES, 2019).

Isto é, a participação em atividades religiosas, as escolhas de doutrinas e o sistema de crenças podem se relacionar à satisfação, além de também influírem substancialmente na concepção que o sujeito configura acerca do mundo, de modo a legitimar o sentido da vida e propiciar o bem-estar (PANZINI et al., 2007).

A religião é um domínio que para ter validade precisa comover e modificar o indivíduo, e não ser meramente um conjunto dotado de moralidade, dogmas e regras, mas, sim, de uma fé que qualifica o encontro real com a deidade cultuada (DINIZ, 2003).

Desta forma, a religião pode ser compreendida como a perfilhação das realidades capitais que a consciência não consegue assimilar, a qual produz a sensação de completude e a união interior quando chega ao ápice do desfrute psíquico. Os mitos (contos) e os ritos (ações) fundamentam todas as crenças espirituais e, portanto, 
são os meios de manifestação do sagrado através das representações desenvolvidas. (BAPTISTA, 2003).

Independente do estilo de vida do idoso, a maior parte deles faz preces por causas como: adquirir saúde, receber paz de espírito e amor, questões familiares e agradecer por favores alcançados (ORLANDO et al., 2008).

A espiritualidade é altamente preponderante nesse período do ciclo vital, de modo que toda uma amostra coletada declarou estar em consonância com alguma religião, já que o engajo a atividades deste cunho possibilita ao idoso a constituição de um liame entre as suas insuficiências e o préstimo de seus talentos. Se isto não acontecer, o sênior será pelo menos apoiado no enfrentamento desta etapa terminal da vida (ARAÚJO, 1999).

Sendo assim, o objetivo geral foi verificar de como os idosos que trabalham apreciam a qualidade de alguns domínios de suas vidas.

Por suas vezes, os objetivos específicos são:

- Compreender como os idosos estão ao continuarem trabalhando após ultrapassarem a idade que os permite cessar estas atividades;

- Promover uma oportunidade aos idosos que trabalham para relatar a condição de alguns domínios de suas vidas;

- Analisar criticamente a condição de alguns domínios de suas vidas.

\section{METODOLOGIA}

\section{PARTICIPANTES}

Este trabalho contou com a participação voluntária de 36 idosos que trabalham, com ou sem registro, contínua ou esporadicamente, com idade igual ou superior a 65 anos (que é a faixa etária designada pela OMS para a aposentadoria); eram $88,90 \%$ homens e 11,10\% mulheres. A idade média é 71,5 anos, a mediana é 71 anos, o 
desvio padrão é de 5,4 e a amplitude de idade é de 22 anos (a menor idade é 65 e a maior é 87).

\section{MATERIAL}

Utilizou-se 36 questionários WHOQOL idênticos para o recolhimento dos dados. Este material foi selecionado devido ao seu reconhecimento internacional para os objetivos citados.

Este questionário convergia em três partes: a primeira era de caracterização do voluntário; a segunda parte era composta de uma série de questões fechadas sobre diversos domínios que integram a concepção geral de qualidade de vida e que, assim, justificam o objetivo desta pesquisa; a última parte comportava outra série de declarações afirmativas e negativas que permitiam ao sujeito exprimir o seu ponto de vista com respeito ao valimento dela em sua vida - em outras palavras, havia sentenças em que o idoso dizia em que nível concordava ou discordava delas tendo em conta o seu contexto.

\section{PROCEDIMENTOS}

Os dados foram coletados acidentalmente em janeiro e fevereiro, isto é, os potenciais participantes da pesquisa (trabalhadores com 65 anos de idade ou mais) eram procurados a esmo e quando encontrados eram abordados pelos pesquisadores instantaneamente.

Primeiro, nos apresentávamos e explicávamos o objetivo do nosso trabalho. Em seguida, se o idoso estivesse em conformidade com o grupo amostral desejado e aceitasse participar, Ihe dávamos o Termo de Consentimento Livre e Esclarecido (TCLE) e o questionário, assim como Ihe províamos todo tipo de aclaração sobre estes documentos e seus itens. É importante enfatizar que o presente artigo é parte de um trabalho maior, o qual foi aprovado no Comitê de Ética e Pesquisa no 017/2005 e na CAAE 005.0.237.000.05. 
Todos os sujeitos encontrados estavam na cidade de São Paulo, sendo 15 na Mooca, seis no Brás, mais seis na Sé, cinco na Zona Cerealista, três na Vila Mariana e um no Cambuci.

\section{RESULTADOS E DISCUSSÃO}

Aqui serão apresentados e discutidos criticamente alguns resultados obtidos nos questionários WHOQOL utilizados por meio das tabelas que se seguem.

Tabela 1 - Estado civil

\begin{tabular}{|l|l|l|}
\hline Situações & F & $\%$ \\
\hline Solteiro & 6 & 16,66 \\
\hline Separado & 4 & 11,11 \\
\hline Casado & 19 & 52,77 \\
\hline Viúvo & 7 & 19,44 \\
\hline Total & $\mathbf{3 6}$ & $\mathbf{1 0 0}$ \\
\hline
\end{tabular}

Fonte: Questionários WHOQOL.

Observa-se na Tabela 1 que mais da metade (52,77\%) dos entrevistados são casados. Outros $19,44 \%$ são viúvos, $16,66 \%$ são solteiros e somente $11,11 \%$ são separados.

Aplicou-se o teste não-paramétrico do Qui-quadrado para saber se existe diferença estatisticamente significante; resultou-se $X_{o}{ }^{2}=9,80$ e $X^{2}{ }_{c}=7,81$, existindo diferença estatisticamente significante. Sabe-se que n.g.I.=3 e $\alpha=0,05$.

Dessa forma, mais da metade dos idosos que trabalham, mantém um relacionamento amoroso fixo e isso pode estar diretamente ligado à ideia relacionada à motivação e interesse no trabalho, pois, de acordo com os estudos realizados por Simkunas e Anjos (2001), após décadas de trabalho, o casamento se torna um fator importante para construção do status social do idoso, já que na perda 
do consorte o indivíduo se sente sozinho, desconsolado e triste. Nesse ínterim, o sujeito sofre por falta de comunicação expressiva e de atenção, perde o seu papel social e passa a ter sentimentos de inutilidade e de falta de expectativa com a vida.

Se considerarmos essas palavras, 30,55\% podem estar sujeitos a um estado psicológico depreciativo e de baixa animosidade por estarem Viúvos ou Separados. Segundo Simkunas e Anjos (2001), todos os sujeitos que passaram por tal experiência mencionam a solidão como um sentimento presente.

Esta condição causada pela perda do cônjuge transverte o status do idoso e, de acordo com Neri (2001b), resulta em modificações coercitivas na autoimagem e autoestima do sênior, além da resistência a novas funções, problemas em planejar o futuro, necessidade de assistência diante das perdas biopsicossociais e perda de ânimo.

No entanto, Almeida e Lourenço (2007) dizem que o amor está à disposição de todos. Mesmo os que nunca se casaram podem e devem procurar parceiros para iniciar uma relação, mas os que se retraem ou se mostram incapazes de se transformar ou evoluir ficam à mercê da solidão e do vazio.

Sobre a maioria que está casada, pode-se supor que o cônjuge seja um atributo que os estimule ou obrigue (a depender da condição socioeconômica de cada um) a permanecer no trabalho, já que ambos os domínios devem constituir o status que o idoso tem de si, conforme Zimerman (2000) e Simkunas e Anjos (2001) dizem.

Tabela 2 - Nível de aceitação da aparência física

\begin{tabular}{|l|l|l|}
\hline Aceitação & F & $\%$ \\
\hline Muito pouco & 2 & 5,55 \\
\hline Médio & 11 & 30,55 \\
\hline Muito & 6 & 16,66 \\
\hline Completamente & 17 & 47,22 \\
\hline
\end{tabular}

RC: 101621

Link de acesso: https://www.nucleodoconhecimento.com.br/psicologia/dominios-davida 


\section{Total}

$36 \quad 100$

Fonte: Questionários WHOQOL.

Observa-se na Tabela 2 que 47,22\% dos participantes aceitam completamente a sua aparência física, enquanto $16,66 \%$ optaram pela afirmação muito. Por outro lado, $30,55 \%$ e 5,55\% avaliam que têm um nível de aceitação relacionado às variáveis Médio e Muito pouco, respectivamente. Nenhum idoso optou pela alternativa Nada, o que fez com que esta variável fosse eliminada da tabela.

Para se averiguar se existe diferença estatisticamente significante, aplicou-se 0 teste do Qui-quadrado. Descobriu-se que $x_{0}^{2}=6,40$ e $x^{2}{ }_{c}=7,81$, não existindo diferença estatisticamente significante. Ressalta-se também que n.g.l. $=3$ e $\alpha=0,05$.

Com relação ao resultado, predominam as opiniões relacionadas a uma perspectiva positiva quanto à aceitação da aparência física, com $63,88 \%$ dos participantes dizendo que a aceitam nas variáveis Muito e Completamente.

Diferente deste resultado, num trabalho semelhante realizado por Colalto (2002) acerca da mesma questão, o resultado obtido referente aos efeitos das mudanças físicas é visto de maneira positiva por somente $40 \%$ dos participantes.

Costa; Bastos e Sales (2008) dizem que a maior parte dos idosos se encontra insatisfeitos com sua aparência física e desejam ter um corpo mais esbelto, uma vez que este fator é importante em sua adaptação biopsicossocial por causa dos estereótipos sobre seu porte físico, considerado frágil. Esses estigmas tendem a fazer com que o idoso veja seu corpo de modo distorcido e tenha representações negativas.

Quanto a isso, Lima (2007) diz que existe um estereótipo de que o envelhecimento é um fenômeno externo. Ao falar sobre a sua própria senioridade, a maioria dos idosos reporta-se ao assunto como se fosse algo fora deles, enquanto o que acontece é que a percepção da velhice, por meio de restrições físicas, quando estas 
já não podem mais ser escondidas, provoca sofrimento, angústia e rejeição desta situação.

Esse conceito de envelhecimento passa pelo poder da mídia. Kuschick e Machado (2016) falam da visão de velhice disseminada através de textos de uma revista popular, na qual foi possível observar hegemonicamente a consolidação de um discurso que compreende a juventude como um valor a ser conquistado e estabelecido, ao passo que a senioridade é entendida como o resultado da inaptidão do sujeito. Em outras palavras, ser jovem trata-se de uma responsabilidade de cada sujeito, que, ao seguir as recomendações periódicas que são publicadas, não envelhecerá.

Rabelo et al. (2008) corroboram a influência do poder midiático ao dizerem que os jovens têm boas concepções acerca de algumas características dos idosos, como no que diz respeito a sua autoimagem, e acreditam haver felicidade na terceira idade. Porém, paradoxalmente consideram que esta fase da vida prenuncia solidão e angústia, de modo a se mostrarem muito desassossegados quanto a este processo em si e declararem preferir a morte que chegar a este estágio e vivenciar estes sentimentos citados como peculiares da velhice.

Essa visão dicotômica que os jovens têm da velhice é fruto de mitos e estereótipos, os quais podem ser fortalecidos pela disseminação de conteúdo impreciso por parte de veículos midiáticos, como a revista estudada por Kuschick e Machado (2016). Esses estereótipos, criadores de uma compreensão parcial e concomitante absoluta dos idosos como sujeitos em situação de inferioridade ou desvantagem em relação aos mais novos, são tão questionáveis que os resultados da Tabela 2 - onde a variável Nada foi eliminada por nenhum participante classificar assim a aceitação de sua aparência física e a opção Muito pouco foi mencionada por somente 5,55\% são incompatíveis com as palavras de Costa; Bastos e Sales (2008) e com os dados apresentados por Colalto (2002). É válido considerar que Zimerman (2000) ainda disserta sobre o mito dos filhos se tornarem pais dos próprios na velhice, desvendando mais um exemplo de má compreensão sobre a senioridade.

RC: 101621

Link de acesso: https://www.nucleodoconhecimento.com.br/psicologia/dominios-da$\underline{\text { vida }}$ 
Vale também considerar as palavras de Jardim; Medeiros e Brito (2019) sobre a peculiaridade da experiência do envelhecimento, a qual rompe com a visão estereotípica e homogênea de ausência de prazer neste estágio. Há idosos que relatam essa adversidade ao reportarem a inexistência de frustrações, conflitos ou dramaticidade nessa fase, do mesmo modo que não identificam sentimento de rejeição e/ou inferioridade diante das mudanças e perdas. Trentini; Xavier e Fleck (2006) denominam esse processo de velhice bem-sucedida, a qual se sucede e se estabelece com a manutenção da saúde tal qual dos jovens adultos.

Sob outra perspectiva dos jovens, Goldenberg (2018) diz que as mulheres dizem que cuidarão de si mesmas quando chegarem à velhice e que as amigas as ajudarão. Já os homens dizem que as mulheres de suas famílias farão isso por eles: esposa, filhas e netas.

No caso específico das mulheres (que são $11,10 \%$ das participantes deste estudo), Fin; Portella e Scortegagna (2017) dizem que as percepções das idosas sobre a beleza corporal na terceira idade se dividem em três categorias: a beleza verbalizada, a experiência estética perante um espelho e a beleza da mulher na velhice.

De acordo com o trio Fin; Portella e Scortegagna (2017), as mulheres idosas, independente das condições socioeconômicas e culturais, reconhecem como beleza a imagem refletida na voga contemporânea com a influência dos padrões estéticos correntes, pois estabelecem um juízo de apreciação no que consideram agradável de ver, sentir e observar. No entanto, a experiência do olhar sobre si revela um contraste entre imagens apreciadas e depreciadas apresentadas pelas diferentes formas de compreender e sentir a velhice. Ao desvendar a aparência do corpo que envelhece, as mulheres confessam os seus sentimentos perante os aspectos dos anos vividos num emaranhado de beleza e fealdade.

Fin; Portella e Scortegagna (2017) completam ao dizer que a beleza na velhice é abstraída como um processo que requer o cuidado de si e de suas relações. 
Constitui-se num olhar atencioso sobre o corpo e a alma que segue regras, condutas e princípios, tais como a prática de exercícios, a manutenção do bom humor, a ocupação com o voluntariado e a procura do médico quando há algum mal-estar. No fim, a percepção da beleza é apreendida na unicidade do ser por meio da valorização e pelo amor dedicado a si próprio.

Esta perspectiva sobre beleza explanada por Fin; Portella e Scortegagna (2017) e, por conseguinte, de aceitação da própria imagem envolve o bem-estar psicológico e engloba a satisfação com a vida nas palavras de Neri (2001a), pois considera a avaliação do indivíduo. Além disso, duas características fulcrais para este bem-estar psicológico são observadas: a capacidade de acomodação às perdas (no caso, da aparência jovial) e a aptidão de assimilar informações positivas sobre si mesmo, que correspondem às imagens belas (que contrastam com as de fealdade) descritas pelo trio.

Estes dados desafiam as palavras de Goldenberg (2018), a qual diz que as mulheres invejam o corpo, a beleza, a juventude, a magreza e a sensualidade de seus pares. $O$ corpo desejado por elas é jovial, esbelto e atraente, que é um modelo precípuo no Brasil.

Goldenberg (2018) continua e ainda diz que as mulheres brasileiras estão entre as maiores consumidoras de produtos e serviços estéticos de todo o mundo, como cirurgia plástica, toxina botulínica, preenchimentos, tintura para cabelo, remédios para emagrecer e moderadores de apetite. Também são as que estão mais insatisfeitas com o próprio corpo, as que mais deixam de sair de casa, ir a festas e até mesmo de trabalhar quando se sentem velhas, gordas e feias.

Veras (1995) continua e diz que no período pós-menopausa ocorrem modificações nos genitais e no porte físico das mulheres. Também podem ocorrer mudanças na autoimagem do seu próprio corpo, de modo a poder achar-se deplorável e sem condições de agradar o seu consorte, o que ocasiona perturbações emocionais. 
O apelo por um corpo aprovado pela sociedade vem desde a juventude, passa pelos meios de comunicação e chega à velhice como um requisito desigual dadas as condições físicas e cíclicas do sujeito. Seja por moda, vaidade pessoal ou autoafirmação simbólica de seu status, o idoso naturalmente está em desvantagem diante dos padrões estéticos exigidos e poderia redefinir o seu conceito de beleza para aceitar sua aparência física com maior satisfação a fim de ter mais qualidade de vida nesse domínio.

Diante disso, pode se, ainda, supor que a permanência no trabalho seja um fortalecedor da autoestima e da aceitação não só de sua aparência física, mas também do seu desempenho cotidiano. Desta forma, os idosos não sentem a velhice como um período de restrições.

Tabela 3 - Insatisfação da relação pessoal com Deus

\begin{tabular}{|c|c|c|}
\hline Insatisfação & $\mathrm{F}$ & $\%$ \\
\hline Concordo Totalmente & 2 & 5,55 \\
\hline Concordo Parcialmente & 2 & 5,55 \\
\hline $\begin{array}{l}\text { Discordo mais que } \\
\text { concordo }\end{array}$ & 1 & 2,77 \\
\hline Discordo Parcialmente & 1 & 2,77 \\
\hline Discordo Totalmente & 30 & 83,33 \\
\hline Total & 36 & 100 \\
\hline
\end{tabular}

Fonte: Questionários WHOQOL.

Os resultados da Tabela 3 indicam que $83,33 \%$ dos idosos Discordam Totalmente de que sua relação com Deus é insatisfatória. Há dois grupos de 5,55\% de entrevistados que optaram pelas alternativas Concordo Totalmente e Concordo Parcialmente e outros dois grupos de 2,77\% que optaram por discordo mais que concordo e Discordo Parcialmente. Somente a alternativa concordo mais que discordo não foi votada pelos sujeitos e por isso foi eliminada da tabela. 
Vale destacar que $x_{0}^{2}=0$ e $x^{2} c=9,48$; já que o teste do Qui-quadrado foi aplicado com a intenção de verificar se existe diferença estatisticamente significante; descobriu-se que não existe a referida diferença. Também vale considerar que n.g.I. $=4$ e $\alpha=0,05$.

A Tabela 4 possui um resultado de total compatibilidade com o da Tabela 3, pois mostra que $83,33 \%$ Concordam Totalmente com a premissa de que sua relação com Deus elimina a sensação de solidão, a mesma quantidade que diz Discordar Totalmente da sugestão de se ter insatisfação na relação pessoal com Deus. É importante destacar que ambas as tabelas não possuem diferença estatisticamente significante e são congruentes entre si mediante seus resultados, o que denota haver ligação entre os aspectos investigados por elas.

Araújo (1999) diz que a espiritualidade é altamente preponderante nesse período do ciclo vital. A razão para tanto é pelo engajo em atividades deste cunho possibilitar ao idoso a constituição de um liame entre as suas insuficiências e o préstimo de seus talentos. Se isto não acontecer, o sênior será pelo menos apoiado no enfrentamento desta etapa terminal da vida.

Em concordância, Panzini et al. (2007) continuam ao dizerem que a religião pode estar relacionada à satisfação. Inclusive, as crenças e doutrinas influem substancialmente na concepção que o sujeito cria sobre o mundo.

Ou seja, nas palavras de Margaca e Rodrigues (2019), a espiritualidade pode ser um elemento favorável ao bem-estar na velhice, até porque a participação em ambientes estimulantes e a presença de oportunidades de evolução se mostram essenciais neste estágio. Assim, a religiosidade pode estar associada a uma maior resiliência na velhice.

Baptista (2003) diz que as religiões são fundamentadas por mitos e ritos que manifestam o sagrado através das representações criadas. Deste modo, considerando a prática de orações como um rito, Orlando et al. (2008) dizem que a maior parte dos idosos reza por questões como gratidão, obtenção de saúde, 
recebimento de paz e amor e por causas familiares, independente do seu estilo de vida.

A oração, em seu sentido mais comum, é a criação de um diálogo entre pessoas. No caso espiritual, compreende-se ser entre o religioso e a divindade, ainda que seja feita conjuntamente com outros adeptos num espaço coletivo. Deste modo, entendese que ela é um meio de comunicação com a figura sacra cultuada com a qual se estabelece uma relação. Relação esta que $88,88 \%$ dos participantes dizem discordar em algum grau quanto a estarem insatisfeitos, conforme os resultados da Tabela 3. Estes dados ainda se compatibilizam com os de Araújo (1999), o qual diz que toda uma amostra coletada (isto é, 100\%) declarou estar em consonância com alguma religião, apesar de não se poder verificar o hiato existente entre esta mesma afinidade e a prática deste rito.

Baptista (2003), assim, define a religião como a perfilhação das realidades capitais que a consciência não consegue assimilar, a qual produz a sensação de completude e a união interior quando chega ao ápice do desfrute psíquico.

Por sua vez, Diniz (2003) conceitua a religião como um domínio que para ter validade precisa comover e modificar o indivíduo, e não ser meramente um conjunto dotado de moralidade, dogmas e regras, mas, sim, de uma fé que qualifica o encontro real com a deidade cultuada.

Enfim, percebe-se que o aspecto religioso é preponderante na opinião dos idosos no que tange à sua qualidade de vida, de modo a demonstrar uma prevalência por respostas de aceitação muito mais polarizada que em outros domínios.

Tabela 4 - Sentimento de solidão eliminado pela relação com Deus

\begin{tabular}{|l|l|l|}
\hline Afago & F & $\%$ \\
\hline Concordo Totalmente & 30 & 83,33 \\
\hline Concordo Parcialmente & 3 & 8,33 \\
\hline
\end{tabular}

RC: 101621

Link de acesso: https://www.nucleodoconhecimento.com.br/psicologia/dominios-davida 


\begin{tabular}{|l|l|l|}
\hline $\begin{array}{l}\text { Discordo mais que } \\
\text { concordo }\end{array}$ & 1 & 2,77 \\
\hline $\begin{array}{l}\text { Discordo Parcialmente } \\
\text { Total }\end{array}$ & 2 & 5,55 \\
\hline
\end{tabular}

Fonte: Questionários WHOQOL.

Na Tabela 4, nota-se que $83,33 \%$ dos sujeitos Concordam Totalmente que não se sentem sozinhos por causa de sua relação com Deus. Outros 8,33\% optaram por Concordar Parcialmente e 5,55\% Discordam Parcialmente. Somente 2,77\% Discordam mais que concordam. As variáveis concordo mais que discordo e Discordo Totalmente não foram citadas e por isso foram descartadas da tabela.

Para saber se existe diferença estatisticamente significante, aplicou-se o teste do Qui-quadrado. Descobriu-se que $x_{0}^{2}=0$ e $x^{2}{ }_{c}=7,81$, não havendo diferença estatisticamente significante. Além disso, considera-se que n.g.l. $=3$ e $\alpha=0,05$.

Esse resultado é igual ao da Tabela 3, na qual $83,33 \%$ dos participantes também dizem Discordar Totalmente da premissa de que não têm uma relação satisfatória com Deus. Na verdade, se há existe uma relação pessoal significativa por consequência não deve haver solidão. As questões abordadas por estas duas tabelas são precisamente similares e congruentes.

Este sentimento é também bem presente na perda do cônjuge, segundo Simkunas e Anjos (2001). A dupla diz que a alternativa encontrada pelos idosos para eliminá-lo é o envolvimento em atividades coletivas. Por outro lado, Almeida e Lourenço (2007) dizem que o amor está à disposição de todos à medida que é expresso em comportamentos. Os sujeitos que se retraem ou se mostram incapazes de se transcender ficam à mercê da solidão e do vazio. Mesmo os que nunca se casaram podem e devem procurar parceiros para iniciar uma relação. No mais, não é possível fazer uma relação entre os dados das Tabelas 1 e 4 pelo estado civil não denotar necessariamente a sensação de solidão.

RC: 101621

Link de acesso: https://www.nucleodoconhecimento.com.br/psicologia/dominios-davida 
Rabelo et al. (2008) também dissertam sobre a solidão ao relatarem ser ela um fator que os jovens associam ao envelhecimento e, por isso, preferirem morrer a sofrer este processo (apesar de acreditarem que é possível ser feliz na velhice e de não duvidarem das capacidades dos idosos). Porém, esta perspectiva é incompatível com os resultados obtidos aqui.

Sob outra perspectiva, Panzini et al. (2007) dizem que a religião pode estar associada à satisfação e, portanto, estar vinculada à felicidade, pois as crenças e doutrinas influem de forma substancial à concepção que o indivíduo configura sobre o mundo.

Ou seja, nas palavras de Margaca e Rodrigues (2019), a religião pode ser um fator propício ao bem-estar na velhice uma vez também que a participação em ambientes motivadores e a presença de oportunidades de progresso têm se mostrado fundamentais na terceira idade. Assim, a religiosidade pode estar associada a uma maior resiliência na velhice.

Araújo (1999) diz que a espiritualidade é altamente preponderante nesse período do desenvolvimento humano, de modo que $100 \%$ da sua amostra declarou estar em conformidade com alguma crença, já que o engajo a atividades deste tipo possibilita ao idoso a constituição de um vínculo entre as suas insuficiências e o préstimo de seus talentos. Se isto não acontecer, o sujeito pelo menos terá suporte no enfrentamento desta etapa final da vida.

Diniz (2003) compreende a religião como um aspecto que para ter validade precisa comover e modificar o sujeito, e não ser meramente um sistema dotado de moralidade, dogmas e regras, mas composto por uma fé que representa o encontro real com o divino.

Por sua vez, Baptista (2003) entende a religião como a perfilhação das realidades capitais que a consciência não consegue assimilar, a qual produz a sensação de completude e a união interior quando chega ao ápice do desfrute psíquico. 
Baptista (2003) também diz que as religiões são baseadas em mitos e ritos capazes de expressar o elemento sacro através dos símbolos constituídos. Assim sendo, Orlando et al. (2008) diz que a maioria dos idosos prática orações por causas como obtenção de paz e amor, gratidão, saúde física e por queixas familiares, independente do seu estilo de vida. As orações podem ser compreendidas como um rito que vincula o idoso à divindade e elimina, como efeito, o seu sentimento de solidão, já que a prece também assume uma forma de relação com o ser sagrado.

Tabela 5 - Existe um verdadeiro propósito para a existência da humanidade

\begin{tabular}{|c|c|c|}
\hline Variáveis & $\mathrm{F}$ & $\%$ \\
\hline Concordo Totalmente & 23 & 63,88 \\
\hline Concordo Parcialmente & 3 & 8,33 \\
\hline $\begin{array}{l}\text { Concordo mais que } \\
\text { discordo }\end{array}$ & 1 & 2,77 \\
\hline Discordo Parcialmente & 1 & 2,77 \\
\hline Discordo Totalmente & 7 & 19,44 \\
\hline Total & 36 & 100 \\
\hline
\end{tabular}

Fonte: Questionários WHOQOL.

É possível perceber nitidamente na Tabela 5 que 63,88\% Concordam Totalmente quanto à suposição de que existe um verdadeiro propósito para a existência humana, enquanto $19,44 \%$ Discordam Totalmente e $8,33 \%$ Concordam Parcialmente. Há três grupos de $2,77 \%$ nas opções concordo mais que discordo, discordo mais que concordo e discordo parcialmente.

Com a intenção de averiguar se há diferença de significância, aplicou-se o teste do Qui-quadrado. Resultou-se: $x_{0}^{2}=8,52$ e $x^{2} c=11,07$; também é válido frisar que n.g.l. $=5$ e $\alpha=0,05$.

Com relação à pergunta de base filosófica, 3/4 dos idosos participantes (75\%) concorda que haja um propósito para a existência humana, uma porcentagem quase

RC: 101621

Link de acesso: https://www.nucleodoconhecimento.com.br/psicologia/dominios-davida 
tão acentuada quanto às observadas nas Tabelas 3 e 4, que investigam aspectos religiosos. É válido considerar as palavras de Panzini et al. (2007), os quais dizem que a religião pode explicar o sentido da vida e influir significativamente na concepção que o sujeito tem do mundo.

Por outro lado, também podemos inferir a relação dessa premissa com a vontade de continuar a viver de uma maneira ativa, enquanto sênior. Martins et al. (2007) dizem que mesmo com um organismo deficitário e fragilizado é possível aos idosos viver com qualidade. Por suas vezes, Simkunas e Anjos (2001) dissertam sobre a importância do consorte nessa fase de vida quando ocorre uma perda; ou seja, o processo de construção interpessoal por meio dessa relação continua na velhice, senão o sujeito não sofreria os impactos descritos pela dupla. Almeida e Lourenço (2007), ainda, dizem que, mesmo para os que não têm um par, o amor está à disposição, desde que o queiram.

Até os jovens têm boas perspectivas acerca das capacidades dos idosos (embora tenham uma visão dual deste estágio), segundo Rabelo et al. (2008), de modo que, em conformidade com Neri (2001a), percebe-se que os seniores demonstram a satisfação com as suas vidas e o seu nível de bem-estar através dessas respostas (embora não sejam muito específicos).

\section{CONSIDERAÇÕES FINAIS}

Os idosos que trabalham demonstram estar majoritariamente satisfeitos com a qualidade dos domínios observados de suas vidas. Foi possível notar em especial uma elevada polarização quanto à religiosidade, de modo a ser este um aspecto quase absoluto na opinião dos participantes, o que está em conformidade com o que Araújo (1999) diz sobre o apoio que este domínio proporciona no enfrentamento desta etapa terminal da vida.

As demais áreas verificadas também receberam dos participantes uma maioria de respostas que denota claramente satisfação, apesar de a distribuição ter sido menos 
concentrada numa única variável. Estima-se que este predomínio se deva ao processo de velhice bem-sucedida, segundo as palavras de Trentini, Xavier e Fleck (2006). Assim, as mudanças inerentes do envelhecimento citadas por Neri (2001a) foram perifericamente observadas no grupo amostral coletado.

Como previamente explanado, este trabalho objetivou investigar a qualidade de alguns domínios da vida de idosos que ainda trabalham por meio de um questionário padronizado e analisar os dados obtidos criticamente através da fundamentação teórica utilizada. Este instrumento pôde quantificar as respostas dos participantes, mensurar diferenças estatísticas e possibilitou a criação de hipóteses baseadas na literatura consultada, porém percebeu-se a presença de lacunas entre estas mesmas respostas e as razões que as fomentaram, de modo a impossibilitar uma análise de maior rigor e acurácia. Desta forma, sugere-se que outros estudos mais detalhados possam ser realizados para investigar qualitativamente estas e outras facetas destes sujeitos (especialmente sobre a vida religiosa, que obteve destaque na polarização das respostas), do mesmo modo que uma replicação deste trabalho com seniores que não trabalham para se comparar os resultados de ambas as classes: trabalhadores e aposentados.

Por fim, espera-se e deseja-se que esta contribuição científica possa cooperar para que haja questionamentos acerca da realidade contextual dos idosos que trabalham com o fim de lhes promover melhores condições de vida tanto nos aspectos abordados (muito embora o grupo amostral tenha demonstrado preeminente satisfação nas respostas) como em outros.

\section{REFERÊNCIAS}

ALMEIDA, Thiago de; LOURENÇO, Maria Luiza. Envelhecimento, amor e sexualidade: utopia ou realidade? Revista Brasileira de Geriatria e Gerontologia, Rio de Janeiro, no 01, v.10, p. 101-114. 2007. Disponível em http://www.scielo.br/scielo. Acessado em 7 de março. 2021. ISSN 19812256. https://doi.org/10.1590/1809-9823.2007.10018. 
ARAÚJO, C. D. S. F. Aspectos religiosos do idoso. In: PETROIANO, A.; PIMENTA L. G. Clínica e cirurgia geriátrica. Rio de Janeiro, Guanabara, p.8-9, 1999.

BAPTISTA, A. L. Espiritualidade na prática clínica. In: Arte Terapia Coleção Imagens da Transformação. Revista POMAR. Rio de Janeiro, no 08, v.10, p. 18-23, 2003.

COLALTO, R. M. C. Qualidade de vida na terceira idade. In: Universidade Camilo Castelo Branco. Monografia como pré-requisito de Trabalho de Conclusão de Curso de graduação em Psicologia - p. 49. São Paulo, 2002.

COSTA, Camila Marinho da; BASTOS, Lidiane Lopes; SALES, Marco Aurélio de. Avaliação da imagem corporal em idosos institucionalizados e não institucionalizados. In: Universidade São Judas Tadeu - USJT. Artigo apresentado no XIV Simpósio Multidisciplinar da USJT realizado em 2008. São Paulo.

DINIZ, L. Espiritualidade e Arte Terapia. In: Arte Terapia Coleção Imagens da Transformação. Revista POMAR. Rio de Janeiro, no 10, v.10, p.109-124, 2003.

FIN, Thais Caroline; PORTELLA, Marilene Rodrigues; SCORTEGAGNA, Silvana Alba. Velhice e beleza corporal das idosas: conversa entre mulheres. Revista Brasileira de Geriatria e Gerontologia, Rio de Janeiro, № 01, v.20, p. 74-84, 2017. Disponível em http://www.scielo.br/scielo. Acessado em 7 de março. 2021. ISSN 1981-2256. https://doi.org/10.1590/1981-22562017020.150096.

FLECK, Marcelo Pio de Almeida; CHACHAMOVICH, Eduardo; TRENTINI, Clarissa Marceli. Projeto WHOQOL-OLD: método e resultados de grupos focais no Brasil. Revista Saúde Pública, São Paulo, v.37, no 6, p.793-799, 2003. Disponível em http://www.scielo.br/scielo. Acessado em 10 de outubro. 2020. https://doi.org/10.1590/S0034-89102003000600016.

GOLDENBERG, Mirian. The invention of a beautiful old age: in search of a freer, happier life. Revista Brasileira de Geriatria e Gerontologia, Rio de Janeiro, ํo 05, 
v.21, p.511-512, 2018. Disponível em http://www.scielo.br/scielo. Acessado em 7 de março. 2021. ISSN 1809-9823.

JARDIM, Viviane Cristina Fonseca da Silva; MEDEIROS, Bartolomeu Figueiroa de; BRITO, Ana Maria de. UM OLHAR SOBRE O PROCESSO DO ENVELHECIMENTO: a percepção de idosos sobre a velhice. Revista Brasileira de Geriatria e Gerontologia, Rio de Janeiro, oㅡ 02, v.9, p.25-34, 2019. Disponível em http://www.scielo.br/scielo. Acessado em 7 de março. 2021. ISSN 1981-2256. https://doi.org/10.1590/1809-9823.2006.09023.

KUSCHICK, Christa Liselote Berger Ramos; MACHADO, Felipe Viero Kolinski. Compre, leia, siga e rejuvenesça! Sobre os sentidos movimentados e construídos por Veja acerca da velhice ao longo de sua história (1968-2014). Galáxia. São Paulo. ํo 32, p.138-150, 2016. Disponível em http://www.scielo.br/scielo. Acessado em 7 de março. 2021. ISSN 1982-2553. https://doi.org/10.1590/198225542016223299.

LIMA, R. A. S. Envelhecer com bem-estar requer conscientização de que a senilidade é inerente ao processo da vida. Revista Psique: Ciência e Vida, n. 18, p. 52-57, 2007.

MARGACA, Clara; RODRIGUES, Donizete. Espiritualidade e resiliência na adultez e velhice: uma revisão. Fractal: Revista de Psicologia. Niterói, oㅡ 02, v. 31, p.150157, 2019. Disponível em http://www.scielo.br/scielo. Acessado em 7 de março. 2021. ISSN 1984-0292. https://doi.org/10.22409/1984-0292/v31i2/5690.

MARTINS, Josiane de Jesus; ALBUQUERQUE, Gelson Luiz de; NASCIMENTO, Eliane Regina Pereira do; BARRA, Daniela Couto Carvalho; SOUZA, Wanusa Graciela Amante de; PACHECO, Wladja Nara Sousa. Necessidades de educação em saúde dos cuidadores de pessoas idosas no domicílio. Texto \& contexto enfermagem, Florianópolis, v. 16, n. 2, p.254-262, Junho/2007. Disponível em http://www.scielo.br/scielo. Acessado em 3 de dezembro. 2020. https://doi.org/10.1590/S0104-07072007000200007.

RC: 101621

Link de acesso: https://www.nucleodoconhecimento.com.br/psicologia/dominios-da$\underline{\text { vida }}$ 
NERI, Anita Liberalesso. Maturidade e velhice. Campinas, Papirus (1ed.), 2001a.

NERI, Anita Liberalesso. Desenvolvimento e envelhecimento. Campinas, Papirus (1ed.), 2001b.

ORLANDO, Cássia; DIAS, João Carlos; BRASIL, Ricardo Taveiros; ARAÚJO, Tiago Coelho; BURITI, Marcelo de Almeida. Religiosidade na dimensão biopsicossocial do sujeito idoso. In: Universidade São Judas Tadeu - USJT. Artigo apresentado no XIV Simpósio Multidisciplinar da USJT realizado em 2008. São Paulo.

PANZINI, Raquel Gehrke; ROCHA, Neusa Sica da; BANDEIRA, Denise Ruschel; FLECK, Marcelo Pio de Almeida. Qualidade de Vida e Espiritualidade. Revista de Psiquiatria clínica. São Paulo. v. 34, n. 1, p.105-115, 2007. Disponível em http://www.scielo.br/scielo. Acessado em 28 de janeiro. 2021.

https://doi.org/10.1590/S0101-60832007000700014.

RABELO, Dóris Firmino; SOUZA, A. P.; GOMES, A. C.; FUJIMOTO, B. H. S.; MOTA, J. J. O.; OLIVEIRA, Lourine Severo. Atitudes de universitários da área da saúde em relação ao idoso e à velhice. In: Centro Universitário de Patos de Minas UNIPAM. Artigo apresentado na XXXVIII Reunião Anual de Psicologia da Sociedade Brasileira de Psicologia realizada em 2008. Uberlândia.

SIMKUNAS, J. B.; ANJOS, K. C. Namoro na velhice: UM estudo sobre os relacionamentos amorosos. In: Universidade São Judas Tadeu. Trabalho de conclusão de curso - Curso de Psicologia, Núcleo de Psicologia Organizacional - p. 66. São Paulo, 2001.

TRENTINI, Clarissa Marceli; XAVIER, Flavio M. F.; FLECK, Marcelo Pio de Almeida. Qualidade de vida em idosos. In: PARENTE, M. A. M. P. Cognição e envelhecimento. Porto Alegre, Artmed (1ed), p. 19-20, 2006.

VELOZ, Maria Cristina Triguero; NASCIMENTO-SCHULZE, Clélia Maria; CAMARGO, Brigido Vizeu. Reflexões sociais do envelhecimento. Psicologia: 
Reflexão e Crítica. Porto Alegre, v. 12, № 12, p. 470-501, 1999. Disponível em http://www.scielo.br/scielo. Acessado em 21 de setembro. 2020. https://doi.org/10.1590/S0102-79721999000200015.

VERAS, Renato Peixoto. Um envelhecimento digno para o cidadão do futuro. Rio de Janeiro, UniATI, 1995.

ZIMERMAN, Guite I. Velhice: Aspectos Biopsicossociais. Porto Alegre, Artmed, 2000.

Enviado: Outubro, 2021.

Aprovado: Novembro, 2021. 